
intervalos de colheita. Horticultura Brasileira 32: 163-167.

\title{
Produtividade de genótipos de milho doce e milho verde em função de intervalos de colheita
}

\author{
José MQ Luz'; Jéssica S Camilo²; Vitor HB Barbieri²; Ramon M Rangel²; Roberta C Oliveira ${ }^{1}$ \\ UFU-ICIAG, Bl. 2E, Campus Umuarama, 38400-902 Uberlândia-MG; jmagno@umuarama.ufu.br; robertacamargoss@gmail.com; \\ ${ }^{2}$ Syngenta Seeds, Rod. BR 452 km 142,38405-230 Uberlandia-MG; jessica.s.camilo@monsanto.com; vitor.barbieri@syngenta.com; \\ ramon.rangel@syngenta.com
}

\section{RESUMO}

O milho doce é uma espécie olerícola de alto valor agregado destinado basicamente ao consumo humano devido ao sabor dos grãos. O Brasil possui potencial para expandir sua produção, porém, mais estudos são necessários para dar suporte e permitir alta produtividade aliada à boa qualidade do produto. Avaliou-se a produtividade e rendimento de grãos de híbridos de milho doce e milho verde em função de intervalos de colheita. O experimento foi instalado na Estação Experimental de Pesquisa da Syngenta Seeds Ltda., no município de Uberlândia-MG. O delineamento experimental foi blocos casualizados em esquema fatorial $8 \mathrm{x} 4$, correspondente a seis híbridos simples experimentais de milho doce (SWC03, SWC04, SWC05, SWC06, SWC07 e SWC08) e dois de milho verde (SWC01 e SWC02) em quatro intervalos de colheita [26, 28, 30 e 32 dias após o florescimento (DAF)], com três repetições. A colheita do milho doce e verde deve ser realizada quando os grãos contiverem entre $72 \%$ a $78 \%$ de umidade (estádio leitoso), o que ocorre entre 20 a 28 DAF. Os híbridos SWC04 e SWC08 detiveram as maiores produtividades de espigas com palha, produtividade de grãos e rendimento de grãos quando colhidos aos 30 DAF $\left(24,38\right.$ e $22,18 \mathrm{t} \mathrm{ha}^{-1} ; 11,70$ e 10,95 t $\mathrm{ha}^{-1}$ e 47,96 e $49,30 \%$, respectivamente).

Palavras-chave: Zea mays subsp. saccharata, análise agronômica, rendimento de grãos.

\begin{abstract}
Productivity of sweet corn and green corn genotypes according to harvest intervals

Sweet corn is a vegetable crop with high added value basically intended for human consumption due to the flavor of the grains. Brazil has the potential to expand its production, but more studies are needed to support and tune high yields and product quality. The productivity and grain yield of hybrid sweet corn and green corn were evaluated according to harvest intervals. The experiment was carried out at the Experimental Research Station of Syngenta Seeds Ltda., in the city of Uberlândia, Minas Gerais state, Brazil. The experimental design was a randomized block in factorial $8 \times 4$, corresponding to six hybrids of sweet corn (SWC03, SWC04, SWC05, SWC06, SWC07 and SWC08), and two hybrids of green corn (SWC01 and SWC02) and four harvest intervals [26, 28, 30 and 32 days after flowering (DAF)], with three replications. Sweet and green corn could be harvested when the grains contain from 72 to $78 \%$ humidity (milky stage), which occurs between 20 to 28 DAF. The hybrids SWC04 and SWC08 presented the highest productivity of ears with straw, productivity of grains and yield when harvested at 30 DAF (24.38 and $22.18 \mathrm{t} \mathrm{ha}^{-1} ; 11.70$ and $10.95 \mathrm{t} \mathrm{ha}^{-1}$ and 47.96 and $49.30 \%$, respectively).
\end{abstract}

Keywords: Zea mays subsp. saccharata, agronomic analysis, grains yield.

(Recebido para publicação em 4 de dezembro de 2012; aceito em 3 de março de 2014) (Received on December 4, 2012; accepted on March 3, 2014)

$\mathrm{O}$ milho doce (Zea mays subsp. saccharata) é classificado como olerícola devido ao alto valor agregado, ao cultivo intensivo e destino ao consumo humano. Pode ser comercializado em conserva ou enlatado (processamento industrial), desidratado ou consumido in natura, congelado na forma de espigas ou grãos, como baby corn ou minimilho se colhido antes da polinização (Souza et al., 1990).

O milho verde refere-se ao milho colhido e consumido ainda fresco, enquanto os grãos estiverem macios (70 a $80 \%$ de umidade) e antes da total conversão do açúcar em amido (Courter et al.,1988). Produtores consideram o milho verde como fonte adicional de renda, pois apresenta valor comercial superior ao milho comercializado na forma de grãos (Caniato et al., 2004).

A diferença entre o milho doce e o milho comum está no teor de açúcares e amido presentes no endosperma (Aragão, 2002), resultantes da ação de genes recessivos individuais ou em associações. Assim, enquanto o milho comum tem em torno de $3 \%$ de açúcar e entre 60 e $70 \%$ de amido, o milho doce tem de 9 a $14 \%$ de açúcar e de 30 a $35 \%$ de amido e o superdoce tem em torno de $25 \%$ de açúcar e de 15 a $25 \%$ de amido (Silva, 1994).

O Brasil cultiva aproximadamente 36 mil hectares de milho doce, sendo $90 \%$ da area plantada concentrada no estado de Goiás pela possibilidade de cultivo o ano todo. A quase totalidade da produção é destinada ao processamento industrial (enlatados e congelados) com uma produtividade média de $13 \mathrm{t} / \mathrm{ha}$, $28 \%$ menos que o alcançado por países de clima temperado (Barbieri et al., 2005). Contudo, o país possui grande potencial para a produção de milho doce para o mercado de exportação europeu e norte americano (Bordallo et al., 2005), especialmente com o desenvolvimento e disponibilidade de novos materiais adaptados ao país (Grigulo et al., 2011). Além disso, o caráter doce de seu endosperma pode atribuir cotações diferenciadas no mercado caracterizando uma alternativa agronômica rentável (Araújo et al., 2006).

As regiões produtoras almejam híbridos com alta capacidade produtiva. 
Por outro lado, as indústrias de processamento exigem que eles apresentem uniformidade quanto à maturação, forma e tamanho das espigas (Kwiatkowski \& Clemente, 2007). Dessa forma, os programas de melhoramento genético de milho doce de empresas privadas visam satisfazer as exigências de agricultores, indústrias de processamento e consumidores (Barbieri et al., 2005).

A colheita do milho doce é realizada quando os grãos ainda estão com alto teor de umidade (superior a 70\%), o que destaca a interferência do estádio fisiológico de maturidade dos grãos na produtividade (Kaukis \& Davis, 1986). Logo, o momento mais propício para colheita é o periodo em que os grãos atingem o ponto máximo de acúmulo de matéria seca e teor de água. Este intervalo, conhecido como período útil de colheita, varia entre genótipos (Barbieri et al., 2005).

A relação entre a taxa de sacarose e amido no momento da colheita do milho doce interfere diretamente na qualidade do produto final. Estes carboidratos apresentam uma relação estreita com o estádio de maturação. Dessa forma, a correlação entre o ponto de colheita com a umidade ideal e a dinâmica de acúmulo de carboidratos no endosperma é de grande importância para a cultura.

O objetivo do trabalho foi avaliar a produtividade de espigas e grãos e o rendimento de grãos de genótipos de milho doce e milho verde em função de intervalos de colheita.

\section{MATERIAL E MÉTODOS}

O experimento foi realizado na Estação Experimental de Pesquisa da Syngenta Seeds Ltda., no município de Uberlândia-MG (18 ${ }^{\circ} 55^{\prime} 8^{\prime \prime} \mathrm{S}$, $48^{\circ} 16^{\prime} 37^{\prime \prime} \mathrm{O}, 887 \mathrm{~m}$ de altitude), de 12 de dezembro de 2009 a 20 de março de 2010. O solo do local é classificado como Latossolo Vermelho Eutrófico.

Foram avaliados seis híbridos simples experimentais de milho doce, classificados em função da diferença quanto à classe de endosperma ( $\mathrm{SWC03}$, SWC04, SWC05, SWC06, SWC07 e SWC08) e dois híbridos experimentais de milho comum (SWC01 e SWC02), no intuito de averiguar a aceitação no mercado dos híbridos comuns comercializados como milho verde. O delineamento experimental foi blocos casualizados (DBC), em esquema fatorial $8 \times 4$, correspondente aos híbridos e dias de colheita [26, 28, 30 e 32 dias após o florescimento (DAF)], totalizando 32 tratamentos com três repetições.

Cada parcela foi constituída por 4 linhas de 4,0 m de comprimento, onde a parcela útil foi constituída das duas linhas centrais $\left(7,2 \mathrm{~m}^{2}\right)$, com o espaçamento de $60 \mathrm{~cm}$ entre linhas, totalizando 64 mil plantas ha-1 . No estádio fenológico V5 procedeu-se ao desbaste ajustando o número de plantas para obter o estande final de 55 mil plantas ha $^{-1}$ e em média 26 plantas na área útil. A semeadura dos híbridos foi realizada mecanicamente.

De acordo com os resultados da análise química do solo efetuou-se a adubação de semeadura com o formulado 08-20-20, na dose de $750 \mathrm{~kg} \mathrm{ha}^{-1}$, e duas coberturas com 20-00-20 (500 kg ha-1) entre os estágios V3 e V6 (12 e 25 dias após semeadura). $\mathrm{O}$ controle de pragas e plantas infestantes foi realizado com pulverizações de inseticidas e herbicidas, respectivamente, registrados para a cultura e em doses recomendadas pelo fabricante. As pragas e doenças foliares foram normalmente controlados com inseticidas e fungicidas recomendados para a cultura e nas doses recomendadas. Não foi realizado o controle químico de doenças na espiga, uma vez que era objetivo do programa de melhoramento fazer avaliação de doenças nos híbridos experimentais. Nenhuma doença que pudesse influenciar as avaliações sensoriais foi encontrada nas espigas.

Para a determinação do ponto de colheita das espigas foi realizado o monitoramento do florescimento feminino, o qual correspondeu ao dia em que $50 \%$ das plantas da parcela útil emitiram pelo menos $1 \mathrm{~cm}$ de estigma visível acima da ponta da espiga. A partir da data de florescimento, realizou-se a colheita manual das espigas das duas linhas centrais de cada parcela aos 26, 28, 30 e 32 dias após o florescimento (DAF), e esta foi sempre realizada no período da manhã. Cerca de cinco espigas com palha de cada parcela útil foram colhidas, acondicionadas em sacos plásticos e encaminhadas ao laboratório da Syngenta Seeds em Uberlândia para realizar as avaliações de produtividade e rendimento de grãos.

No laboratório foram realizadas as avaliações de umidade (método da estufa a $105^{\circ} \mathrm{C}$ por 24 horas, calculando-se a umidade $\mathrm{U}(\%)=[$ Peso úmido - Peso seco)/Peso Úmido * 100], produtividade de espigas (pesagem de cinco espigas da parcela útil com palha, em $\mathrm{tha}^{-1}$ ), produtividade de grãos (os grãos das cinco espigas foram cortados rente ao sabugo com auxílio de uma faca e pesados em uma balança de precisão, em $\mathrm{t} \mathrm{ha}^{-1}$ ) e rendimento de grãos (obtido da divisão do peso de grãos pelo peso de espigas com palha, em porcentagem).

Os dados de produtividade e rendimento foram submetidos à análise da variância, pelo teste $\mathrm{F}$, e as médias comparadas pelo teste de Tukey a $5 \%$ de significância, com auxílio do programa SISVAR (Ferreira, 2008). Com os dados de umidade foram feitas regressões polinomiais.

\section{RESULTADOS E DISCUSSÃO}

A umidade no momento de colheita variou entre 54 e $77 \%$ (Figura 1). Segundo Silva \& Paterniani (1986) e Kwiatkowski \& Clemente (2007) a umidade ideal das espigas no momento da colheita do milho doce tanto para consumo in natura quanto para processamento industrial é em torno de 70 a $80 \%$. Para os genótipos de milho verde, é especialmente importante atentar-se para a umidade ideal, pois nesta fase os grãos ainda permanecem em estádio leitoso, o que por sua vez permite o consumo como milho verde, isto é, os grãos apresentam-se macios e os açúcares não foram totalmente convertidos a amido (Courter et al.,1988).

Observou-se que a colheita realizada entre 28 e 30 dias após o florescimento (DAF) correspondeu à umidade ideal para todos os híbridos de milho doce e para o híbrido de milho verde SWC 01 (Figura 1); colheitas mais tardias reduziram a umidade. $\mathrm{O}$ genótipo $\mathrm{SWC02}$ apresentou declínio na umidade chegando à umidade mínima estimada de 


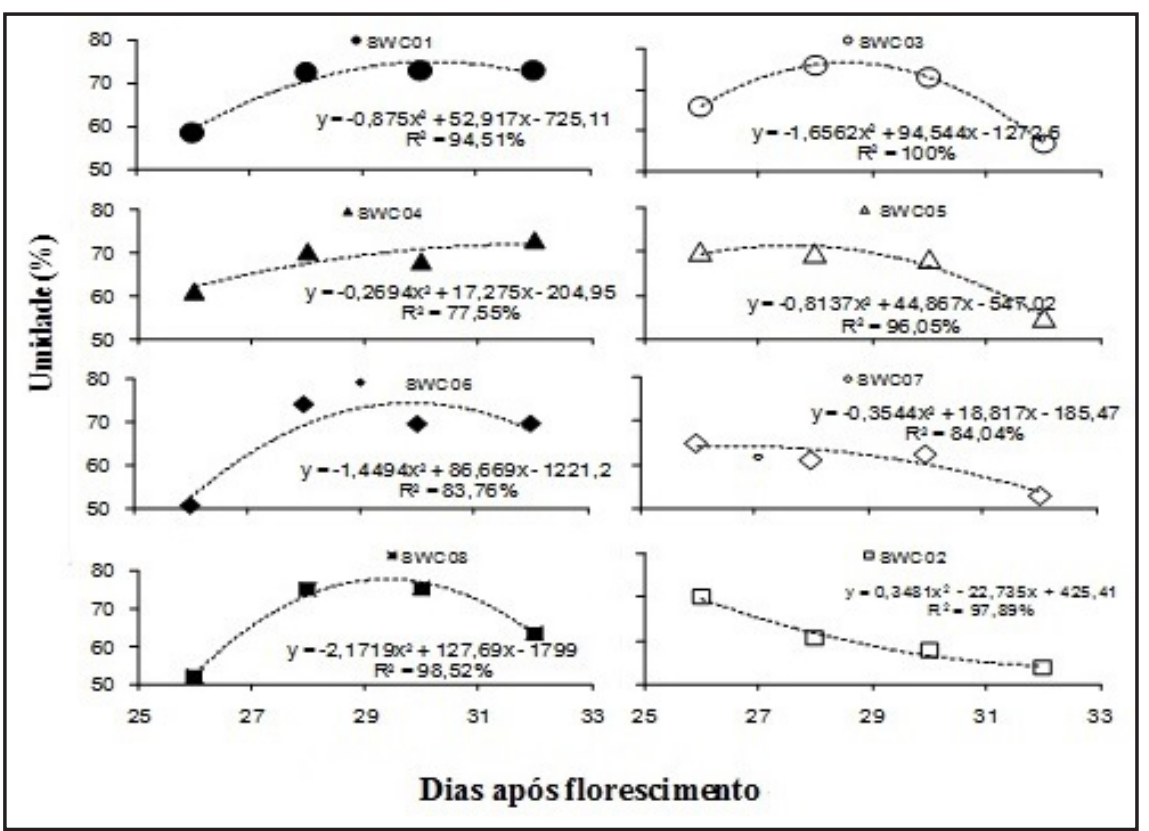

Figura 1. Umidade (\%) de grãos de híbridos de milho doce (SWC03, SWC04, SWC05, SWC06, SWC07 e SWC08) e milho verde (SWC01 e SWC02) em função de intervalos de colheita [humidity (\%) of sweet corn grains (SWC03, SWC04, SWC05, SWC06, SWC07 and SWC08) and green corn (SWC01 and SWC02) hybrids according to harvest intervals]. Syngenta, Uberlândia, 2010.

54\% aos 33 DAF (Figura 1). Portanto, para este genótipo, a colheita deve ser realizada preferencialmente aos $26 \mathrm{DAF}$ pois a conversão dos açucares em amido neste híbrido altera a composição química. Isso interfere diretamente no sabor e na textura dos grãos, relacionados com as classes de endosperma (Tracy, 2001) e a aceitabilidade pelos consumidores.

É importante que se colha na umidade ideal, pois esta influencia diretamente a qualidade pós-colheita do produto. No mercado de processamento industrial, quando os grãos apresentam alto teor de umidade, há uma redução no rendimento de grãos, resultante do número elevado de espigas no estádio cristal ou "bolha d'água". Vale lembrar que as indústrias de processamento permitem no máximo um total de $8 \%$ de espigas nesse estádio (Pereira Filho et al., 2002).

$\mathrm{O}$ milho doce, por ser um produto destinado ao consumo humano na forma in natura e em conserva, requer um cuidado especial na determinação do momento ideal de colheita, uma vez que não se busca apenas elevada produtividade mas sim um conjunto de fatores que leva ao produto final de boa qualidade com alto valor agregado no mercado (Barbieri et al., 2005). Portansignificantly different (Tukey test, 5\%)]. significativa para produtividade média de espigas (Tabela 1) e produtividade média de grãos (Tabela 2) entre os genótipos aos 28 DAF. Já aos $30 \mathrm{DAF}$, os híbridos SWC04, SWC06, SWC08 e SWC01 apresentaram as maiores produtividades médias de espigas com palha (21,79 a 24,38 t ha-1) e grãos (8,87 a 11,70 $\left.\mathrm{t} \mathrm{ha}^{-1}\right)$ (Tabelas 1 e 2). A produtividade com palha também é um importante parâmetro a ser considerado na comercialização de milho doce, devido à maior conservação dos grãos (Oliveira et al., 2006).

Barbieri et al. (2005), estudando população e espaçamento na cultura do milho doce, comparando um híbrido simples com um híbrido triplo, não observaram diferenças entre eles. Em ambos, a produtividade aumentou linearmente com o acréscimo do estande. A produtividade média de espiga com palha estimada pela equação obtida pelos autores, considerando a mesma população deste trabalho, foi de 18,78 t ha $\mathrm{a}^{-1}$. Barbieri et al. (2005), estimaram também a produtividade de grãos para um híbrido simples de milho doce (MD 2001) em 9,30 t ha ${ }^{-1}$, sendo os híbridos simples experimentais testados no presente trabalho: SWC04; 06 e 08, mais produtivos $\left(10,14\right.$ a 11,70 t ha $\left.^{-1}\right)$ (Tabela 2). Portanto, observa-se que os genóti-

Tabela 1. Produtividade média $\left(\mathrm{t} \mathrm{ha}^{-1}\right)$ de espigas com palha de híbridos de milho doce (SWC03, SWC04, SWC05, SWC06, SWC07 e SWC08) e milho verde (SWC01 e SWC02) em função de intervalos de colheita [average productivity $\left(\mathrm{t} \mathrm{ha}^{-1}\right)$ of sweet corn ears with straw (SWC03, SWC04, SWC05, SWC06, SWC07 and SWC08) and green corn (SWC01 and SWC02) hybrids according to harvest intervals]. Syngenta, Uberlândia, 2010.

\begin{tabular}{lcccccccc}
\hline \multirow{2}{*}{ Híbridos } & \multicolumn{7}{c}{ Dias após florescimento (DAF)* } \\
\cline { 2 - 9 } & \multicolumn{7}{c}{$\mathbf{2 6}$} & \multicolumn{2}{c}{$\mathbf{2 8}$} & $\mathbf{3 2}$ \\
\hline SWC01 & 20,99 & ABC ab & 17,8 & A bc & 21,79 & A a & 16,49 & B c \\
SWC02 & 17,99 & BC b & 16,18 & A c & 15,19 & B b & 21,74 & A a \\
SWC03 & 17,69 & C ab & 16,79 & A b & 16,17 & B b & 20,83 & A a \\
SWC04 & 21,94 & ABC ab & 16,44 & A b & 24,38 & A a & 16,00 & B a \\
SWC05 & 17,12 & C b & 14,95 & A b & 15,79 & B b & 22,86 & A a \\
SWC06 & 23,96 & ABC ab & 16,16 & A b & 22,44 & A a & 16,14 & B b \\
SWC07 & 18,47 & BC b & 14,32 & A c & 15,28 & B bc & 23,70 & A a \\
SWC08 & 23,01 & ABC ab & 16,9 & A b & 22,18 & A a & 13,98 & B b \\
\hline CV (\%) & \multicolumn{7}{c}{8,35} \\
\hline
\end{tabular}

*Médias seguidas por letras maiúsculas distintas na coluna comparando híbridos e letras minúsculas distintas na linha comparando DAF apresentam diferenças significativas pelo teste de Tukey, a 5\% de significância [means followed by uppercase letters distinct in the column comparing hybrids and lowercase letters distinct in the line comparing DAF are 
Tabela 2. Produtividade média ( $\left.\mathrm{t} \mathrm{ha}^{-1}\right)$ de grãos de híbridos de milho doce (SWC03, $\mathrm{SWC04}$, SWC05, SWC06, SWC07 e SWC08) e milho verde (SWC01 e SWC02) em função de intervalos de colheita [average productivity $\left(\mathrm{t} \mathrm{ha}^{-1}\right)$ of grains of sweet corn (SWC03, SWC04, SWC05, SWC06, SWC07 and SWC08) and green corn (SWC01 and SWC02) hybrids according to harvest intervals]. Syngenta, Uberlândia, 2010.

\begin{tabular}{lrrrrrrrr}
\hline \multirow{2}{*}{ Híbridos } & \multicolumn{8}{c}{ Dias após florescimento (DAF)* } \\
\cline { 2 - 10 } & \multicolumn{9}{c}{$\mathbf{2 6}$} & \multicolumn{3}{c}{$\mathbf{3 0}$} & \multicolumn{3}{c}{$\mathbf{3 2}$} \\
\hline SWC01 & 7,49 & ABC a & 6,98 & A a & 8,87 & AB a & 6,51 & CD a \\
SWC02 & 7,74 & BC a & 6,83 & A b & 6,49 & B b & 9,45 & AB a \\
SWC03 & 6,83 & C a & 5,94 & A a & 6,12 & B a & 7,31 & ACBD a \\
SWC04 & 9,35 & AB a & 5,69 & A b & 11,70 & A a & 6,30 & CD b \\
SWC05 & 5,54 & C b & 6,29 & A b & 6,46 & B b & 9,09 & ABC a \\
SWC06 & 9,80 & AB a & 4,76 & A b & 10,14 & A a & 6,81 & BCD b \\
SWC07 & 7,58 & BC a & 5,19 & A b & 6,37 & B b & 9,85 & A a \\
SWC08 & 10,93 & A a & 7,47 & A b & 10,95 & A a & 5,34 & D b \\
\hline CV (\%) & \multicolumn{9}{c}{14,73} & & \\
\hline
\end{tabular}

*Médias seguidas por letras maiúsculas distintas na coluna comparando híbridos e letras minúsculas distintas na linha comparando DAF apresentam diferenças significativas pelo teste de Tukey, a 5\% de significância [means followed by uppercase letters distinct in the column comparing hybrids and lowercase letters distinct in the line comparing DAF are significantly different (Tukey test, $5 \%$ )].

Tabela 3. Rendimento de grãos médio (\%) de híbridos de milho doce (SWC03, SWC04, SWC05, SWC06, SWC07 e SWC08) e milho verde (SWC01 e SWC02) em função de intervalos de colheita [average grain yield (\%) of sweet corn (SWC03, SWC04, SWC05, SWC06, SWC07 and SWC08) and green corn (SWC01 and SWC02) hybrids according to harvest intervals]. Syngenta, Uberlândia, 2010.

\begin{tabular}{lcrrrrrrr}
\hline \multirow{2}{*}{ Híbridos } & \multicolumn{8}{c}{ Dias após florescimento (DAF)* } \\
\cline { 2 - 9 } & \multicolumn{2}{c}{$\mathbf{2 6}$} & \multicolumn{2}{c}{$\mathbf{3 0}$} & $\mathbf{3 2}$ \\
\hline SWC01 & 35,65 & B a & 38,92 & AB a & 40,65 & AB a & 39,50 & A a \\
SWC02 & 42,58 & AB a & 42,17 & A a & 42,67 & AB a & 43,50 & A a \\
SWC03 & 35,99 & B a & 35,15 & AB a & 37,81 & B a & 35,10 & A a \\
SWC04 & 42,70 & AB ab & 33,86 & AB b & 47,96 & AB a & 39,05 & A ab \\
SWC05 & 31,76 & B b & 41,97 & A a & 40,84 & AB ab & 39,76 & A ab \\
SWC06 & 40,82 & AB a & 29,32 & B b & 45,08 & AB a & 42,04 & A a \\
SWC07 & 41,31 & AB a & 35,85 & AB a & 41,70 & AB a & 41,58 & A a \\
SWC08 & 47,49 & A a & 43,90 & A ab & 49,30 & A a & 37,84 & A b \\
\hline CV (\%) & \multicolumn{7}{c}{10,88} \\
\hline
\end{tabular}

*Médias seguidas por letras maiúsculas distintas na coluna comparando híbridos e letras minúsculas distintas na linha comparando DAF apresentam diferenças significativas pelo teste de Tukey, a 5\% de significância [means followed by uppercase letters distinct in the column comparing hybrids and lowercase letters distinct in the line comparing DAF are significantly different (Tukey test, $5 \%$ )].

pos deste estudo são opções potenciais para o mercado.

Oliveira Júnior et al. (2006), estudando híbridos experimentais de milho verde, obtiveram produtividade média de espigas com palha de $12 \mathrm{tha}^{-1}$. Os autores relataram que no sistema de produção de milho verde de média a grande escala, normalmente as espigas são transportadas até o local de espigas e grãos gera benefícios tanto para o agricultor quanto para a indústria. Isso se justifica pelo fato da maior rentabilidade do agricultor com híbridos mais produtivos, os quais podem produzir mais em menor área. Além disso, a indústria pode comprar a matéria-prima com menor custo, pois há redução de gastos com logística e colheita (Barbieri et al., 2005).

$\mathrm{Na}$ colheita realizada aos 28 dias após o florescimento, o híbrido SWC06 apresentou o menor rendimento de grãos (29,32\%), enquanto os demais genótipos não diferiram estatisticamente entre si (Tabela 3). Já aos 30 DAF, o híbrido SWC03 apresentou o menor rendimento de grãos $(37,81 \%)$. Considerando todos os intervalos de colheita, o maior rendimento de grãos foi do híbrido SWC08 quando colhido aos 30 DAF $(49,3 \%)$ (Tabela 3).

Esta variável é um importante parâmetro de produção, uma vez que é fundamental na escolha de um híbrido de maior rentabilidade econômica no processamento industrial. Segundo Barbieri et al. (2005), um híbrido de elevado rendimento de grãos resulta em economia de energia elétrica, equipamentos e mão-de-obra durante seu processamento na indústria.

A partir da avaliação da produtividade de grãos, espigas e rendimento de grãos, observou-se que os híbridos de milho doce SWC04 e SWC08 apresentaram os melhores resultados para todas as características avaliadas aos $30 \mathrm{DAF}$. Todavia, a avaliação de desempenho de um híbrido de milho doce não deve ser limitada apenas à sua produtividade e rendimento de grãos, uma vez que o híbrido deve satisfazer às exigências do agricultor e/ou indústria e/ou consumidor.

Apesar da alta produtividade e rendimento de grãos destes dois híbridos experimentais (SWC04 e SWC08), fazem-se necessários mais estudos, para avaliação rigorosa de outras características que são essenciais para a indústria (formato da espiga e comportamento após o processamento), para o agricultor (qualidade de sementes, tolerância a pragas e doenças) e para o consumidor (cor, sabor, textura e aparência).

Concluiu-se que a colheita do milho 
doce e verde deve ser realizada quando os grãos contêm entre 70 e $78 \%$ de umidade (estádio leitoso), o que ocorre entre 20 a 28 dias após o florescimento (DAF). Os híbridos SWC04 e SWC08 apresentam as maiores produtividades de espigas com palha, produtividade e rendimento de grãos quando colhidos aos 30 DAF $\left(24,38\right.$ e 22,18 t ha ${ }^{-1} ; 11,70$ e $10,95 \mathrm{t} \mathrm{ha}^{-1}$ e 47,96 e $49,30 \%$, respectivamente).

\section{REFERÊNCIAS}

ARAGÃO CA. 2002. Avaliação de híbridos simples braquiticos de milho super doce (Zea mays) portadores do gene shrunken (sh2sh2) utilizando esquema dialélico parcial. Botucatu: UNESP. 101p. (Tese doutorado). Disponível em http://www.acervodigital. unesp.br/handle/123456789/26301. Acessado em 2 de março de 2012.

ARAUJO EF; ARAUJO RF; SOFIATTI V; SILVA RF. 2006. Qualidade fisiológica de sementes de milhodoce colhidas em diferentes épocas. Bragantia 65: 687-692. Disponível em http://www.scielo.br/pdf/brag/v65n4/20.pdf. Acessado em 10 de maio de 2012.

BARBIERI VHB; LUZ JMQ; BRITO CH; DUARTE JM; GOMES LS; SANTANA DG. 2005. Produtividade e rendimento industrial de híbridos de milho doce em função de espaçamento e populações de plantas. Horticultura Brasileira 23: 826-830. Disponível em http://www.scielo.br/pdf/hb/ v23n3/a27v23n3.pdf. Acessado em 22 de maio de 2012.

BORDALLO PN; PEREIRA MG; AMARAL JÚNIOR AT; GABRIEL APC. 2005. Análise dialélica de genótipos de milho doce e comum para caracteres agronômicos e proteína total. Horticultura Brasileira 23: 123-127. Disponível em http://www.scielo.br/pdf/hb/ v23n1/a26v23n1.pdf. Acessado em 23 de março de 2012.

CANIATO FF; GALVÃO JCC; FINGER FL; RIBEIRO RA; MIRANDA GV; PUIATTI M. 2004. Composição de açúcares solúveis totais, açúcares redutores e amido nos grãos verdes de cultivares de milho na colheita. Revista Brasileira de Milho e Sorgo 3: 38-44.

COURTER JW; RHODES AM; GARWOOD DL; MOSELY PR. 1988. Classification of vegetables corns. HortScience 23: 449- 450.

FERREIRA DF. 2008. SISVAR: um programa para análises e ensino de estatística. Revista Symposium 6: 36-41.

GRIGULO ASM; AZEVEDO VH; KRAUSE W; AZEVEDO PH. 2011. Avaliação do desempenho de genótipos de milho para consumo in natura em Tangará da Serra, MT, Brasil. Bioscience Journal 27: 603-608. Disponível em http://www.seer.ufu.br/index. $\mathrm{php} /$ biosciencejournal/article/view/8247. Acessado em 21 de fevereiro de 2012.

KAUKIS K; DAVIS DW. 1986. Sweet corn breeding. In: BASSETT MJ (ed). Breeding vegetable crops. Connecticut: The Avi Publishing Company, p. 477-512.
KWIATKOWSKI A; CLEMENTE E. 2007. Características do milho doce (Zea mays) para industrialização. Revista Brasileira de Tecnologia Agroindustrial 1: 93-103. Disponível em http://revistas.utfpr.edu.br/pg/ index.php/rbta/article/view/263/231. Acessado em 14 de janeiro de 2012.

OLIVEIRA JUNIOR LFG; DELIZA R; BRESSAN-SMITH R; PEREIRA MG; CHIQUIERE TB. 2006. Seleção de genótipos de milho mais promissores para o consumo in natura. Ciência de Tecnologia de Alimentos 26: 159-165. Disponível em: http://www. scielo.br/pdf/cta/v26n1/28865.pdf. Acessado em 23 de março de 2012.

PEREIRA FILHO IA; CRUZ JC; GAMA EEG. 2002. Cultivares para o consumo verde. In: PEREIRA FILHO IA (ed). O cultivo do milho verde. Brasília: Embrapa. p.17-30. Disponível em: http://www.cnpms.embrapa. br/publicacoes/publica/2002/circular/Circ_15. pdf. Acessado em 30 de abril de 2012.

SILVA PSL; PATERNIANI E. 1986. Produtividade de "milho verde" e de grãos de cultivares de Zea mays. Ciência e Cultura 38: 707-712.

SILVA N. 1994. Melhoramento de milho doce. In: ENCONTRO SOBRE TEMAS DE GENÉTICA E MELHORAMENTO, 11, Piracicaba. Anais... 11: 45-49.

SOUZA IRP; MAIA AHN; ANDRADE CLT. 1990. Introdução e avaliação de milho doce na região do baixo Parnaíba. Teresina: EMBRAPA-CNPA. 7p.

TRACY WF. 2001 Sweet corn. In: Hallauer AR (ed) Speciality corn. $2^{\text {nd }}$. Boca Raton Press. p.155-198. 